Document downloaded from:

http://hdl.handle.net/10251/113028

This paper must be cited as:

Curiel-Esparza, J.; Canto-Perello, J. (2012). Understanding the major drivers for implementation of municipal sustainable policies in underground space. The International Journal of Sustainable Development and World Ecology. 19(6):506-514.

doi:10.1080/13504509.2012.732973

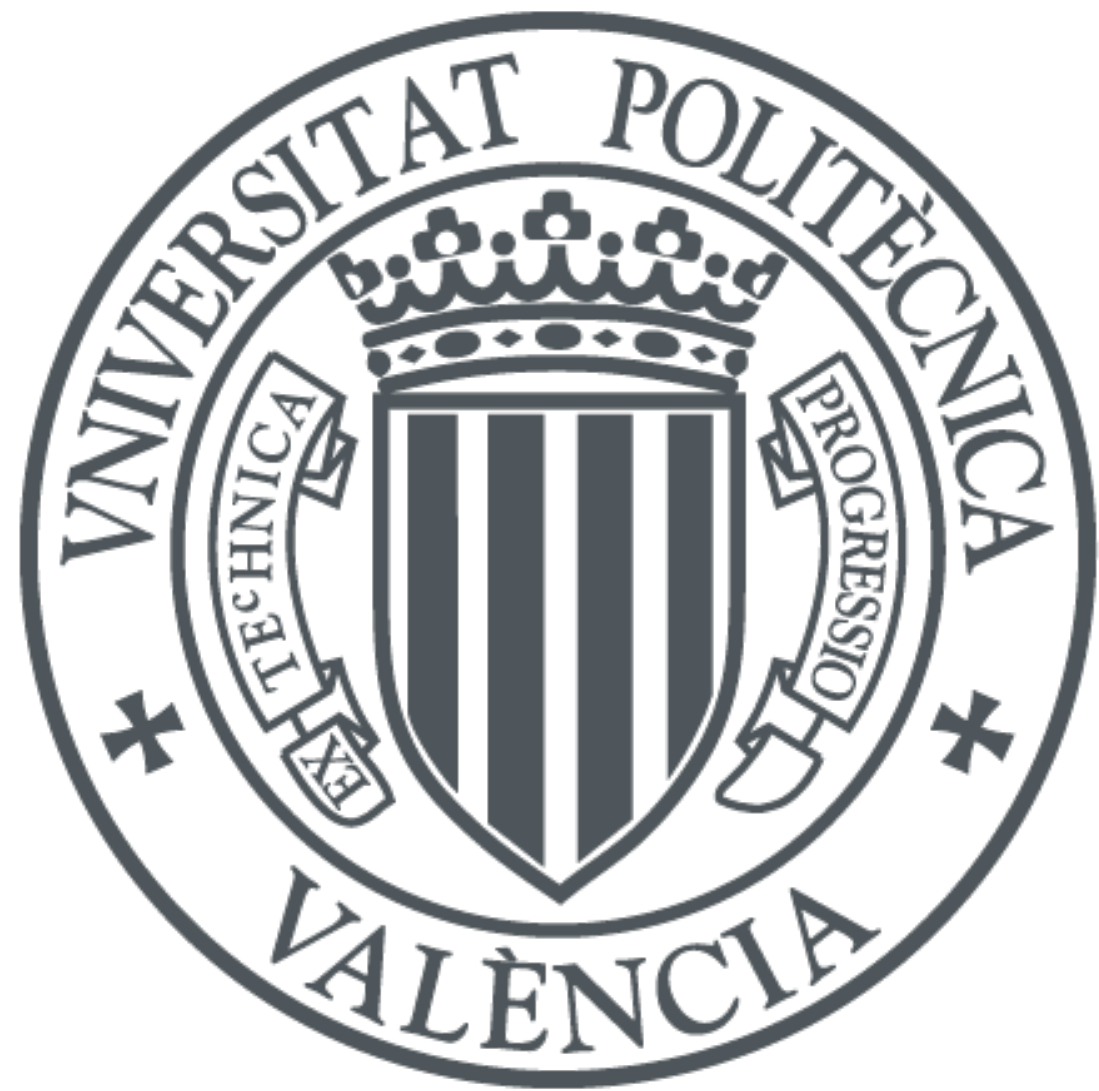

The final publication is available at

https://doi.org/10.1080/13504509.2012.732973

Copyright TAYLOR \& FRANCIS INC

Additional Information 
Understanding the major drivers for implementation of municipal sustainable policies in underground space

Jorge Curiel-Esparza ${ }^{a^{*}}$, Julian Canto-Perello $^{\mathrm{b}}$

aphysical Technologies Center, Universitat Politecnica de Valencia, Valencia, Spain.

${ }^{b}$ Department of Construction Engineering and Civil Engineering Projects, Universitat Politecnica de Valencia, Valencia, Spain.

*Corresponding author: Universitat Politecnica de Valencia, Camino de Vera s/n 46022 Valencia, Spain; Email: jcuriel@upv.es.

Tel.: +34-96-387-7520; Fax: +34-96-387-7529. 


\title{
Understanding the major drivers for implementation of municipal sustainable policies in underground space
}

\begin{abstract}
Because of the expanding population in our cities with its demands for more diversified services, we cannot afford a piecemeal type of urban underground growth. Utilization of the urban street system for buried utilities has a serious adverse effect on other street functions because of the continuing necessity to perform excavations for the repair of existing lines and the installation of new ones. The excavations not only are a serious cause of traffic delay and congestion but also create noise and aesthetic disturbances, and result in excessive street maintenance requirements and in shortened overall street life. Consider the enhancing effects in quietness on abutting properties and users of the street, and the benefits become very great. Unfortunately the lack of data and the difficulty in quantifying the intangibles has made it impossible to arrive at a reasonably accurate figure of overall negative impact on the urban environment of street cuts. However, if drivers are sufficiently strong to merit the use of utility tunnels, then sustainable municipal policies improving living quality will be implemented.
\end{abstract}

Keywords: sustainable underground planning; municipal policies; urban utilities; utility tunnels; urban environment

\section{Introduction}

The qualities and attractiveness of the cities are not only determined by the fulfillment of the material economic needs of their citizens, but also by the social and environmental conditions which prevail. Environmental conditions in urban areas are a source of critical concern, since urban populations are particularly exposed to the combined effects of air and water pollution, problems of waste disposal and derelict land, noise and congestion. The urban environmental problems exist in all countries, although they are a cause for variable degrees of concern, from acute and immediate to minor and local. But without any doubt, there is an increasing interest on the need for sustainable planning in our cities (Booi and Berg 2010; Choon et al. 2011). Moreover, it is part of European Union policy to achieve a high level of health and environmental protection, and one of the objectives to be pursued is sustainable development (Steurera and Bergerb 2011).

Urban underground constitutes a "space", able to accommodate activities which it is difficult, impossible or unacceptable to locate on the surface. It offers a natural protection to whatever is placed underground. The containment created by underground structures has the advantage of protecting the surface environment from the risks and disturbances inherent in certain activities (Canto-Perello and Curiel-Esparza 2003; Sterling and Godard 2000). The resource 
represented by the underground has generally been undervalued by society and the result has led to a lack of effective planning for the increasing uses that develop over time in growing cities (Duffaut 1996; Duffaut and Labbe 2002). Underground space is an environmental entity and a natural resource in its own right and can be damaged or changed by human activities (Canto-Perello et al. 2009; Carmody and Sterling 1993). Underground space cannot be returned to their pre-construction condition. Therefore, underground space use must be planned in a sustainable manner. According to ITACUS (ITACUS 2011), underground infrastructure contributes to sustainability of the environment in many ways: saving natural resources, including land, water, and biodiversity; reducing air pollution (mainly in the transport sector, though also for others, such as underground sewage treatment facilities) and unnecessary visual and noise intrusion; creating opportunities for less energy use and waste generation (compact city); creating structures less impacted by earthquakes and other catastrophic events; and enhancing of overall landscape and environmental quality. Facilities placed fully underground (once constructed) do not impact the surface aesthetic and can allow natural ground surfaces and flora that maintain the natural ecological exchanges of thermal radiation, convection and moisture exchange between the ground and the air. Underground infrastructure allows a reduction of land area covered by manmade structures. Urban underground space must be considered as a finite and non-renewable resource. Sustainable development of underground space not just calls for using underground space, but using it to combine functions and to create value in doing so for society (Thibault et al. 2003; Wang et al. 2008). Establishing future sustainable strategies in urban underground engineering consists of the ability to lessen the use of traditional trenching (Cano-Hurtado and CantoPerello 1999; Curiel-Esparza et al. 2004; Zhang 2009).

In our cities, nearly all of the underground space down to 6 meters beneath the pavement level is filled with urban utilities. In narrow streets like those found in European historical towns, there is often not enough space for all the conduits, so they have to be placed closer together or above each other. This density of utilities has been ironically termed "the spaghetti subsurface problem" (Oude 1992) by municipal engineers, see Figure 1. After installation under streets, utility systems are far from unobtrusive. Their presence is well indicated by the seemingly ceaseless opening of the streets to make repairs and provide new and larger systems and services. These openings, often called street cuts, cause serious delays to traffic, create noise and aesthetic disturbances, and result in excessive street maintenance requirements and in shortened overall street life. Moreover, the cost of road congestion in OECD countries is estimated to be equivalent to about 2 per cent of the GDP (Godard 2008). The sum of aesthetic considerations; the proliferation of utility types, services and expansions; the scarcity and cost of available rights-of-way; the effect of street cuts on traffic and people; the increasing population densities of urban areas; and other considerations serve to question the appropriateness of past and present utility installation practices. Solution rests in the use of utility tunnels in conjunction with an adequate urban planning and governance. A utility tunnel, see Figure 2, is defined as an underground structure containing one or more utility systems, permitting the installation, maintenance and removal of the system without the 
necessity of making street cuts or excavations. Potable water, steam, hot water, chilled water, electric power, telephone, telegraph, television coaxial cable and other communication circuits are generally accommodated in existing utility tunnels. Gas lines are included less frequently, but several countries have altered their policy of excluding gas in recent years. Gas systems impose no problems in association with other systems except for the remote possibility of explosions resulting from leaks and rupture. Storm and sanitary sewers are included only where this is possible by gravity flow. No instances were found where the sewers were converted to pressure systems for the purpose of including them in a utility tunnel. Pneumatic postal tubes are contained in portions of the London utility tunnel systems.

Many countries have walk-through tunnels which house one or more urban utility lines, but few countries have installed comprehensive utility tunnel systems as an accepted alternative to individual direct burial of utilities. Although each tunnel system will be referred to as a utility tunnel this is not to imply that the term is used worldwide, but only that the basic definition applies. In Paris the appropriate term would likely be technical galleries; in London mixed services subways; in Japan common conduit; in Madrid service galleries; in Germany collecting channels or transversable utility channels. In the United States and Canada the terms pipe galleries, utility chases, and utilidors have also been used. In order to understand key drivers in urban underground policies, significant utility tunnel facilities have been analyzed. Based on these, it is possible to reconstruct much of the past motivation for utility tunnels and study some of the practices which influence the current and future of utility tunnel's planning.

Summarizing, the primary drivers of utility tunnel systems are the reduction or elimination of street cuts, eliminating interferences with traffic, reducing street noise and damages to other utilities; increase or expansion of utilities without disruption of traffic; and the reduction of utility rights of way requirements (see Figure 3). The main disadvantages are the increased cost and complexity in characterizing the existing space, coordinating installation and ensuring compatibility for maintenance activities (Abdul Salam 2007; Canto-Perello and

Curiel-Esparza 2001; Curiel-Esparza and Canto-Perello 2005). However, advantages of utility tunnels indubitably outweigh the disadvantages in quiet areas. The aim of this paper is to promote the use of utility tunnels in municipal policies to achieve quietness in the urban environment, even though their organizational structures and operational risks might seem discouraging.

\section{Public pressure drivers}

Utilities have traditionally been permitted to utilize the street or highway right-of-way for location in either an aboveground or underground mode. Until recently, location of utilities in the underground case generally has not been accomplished in any systematic manner. This 
has resulted in a veritable maze under the street rights-of-way in high density urban districts. After installation under streets, utility systems are far from unobtrusive. Their presence is well indicated by the seemingly ceaseless opening of the streets to make repairs and provide new and larger systems and services. Failures on power lines and telecommunication cables are reduced by $80 \%$ when utilities are placed in-tunnel. These openings, often called street cuts, cause serious delays to traffic, create noise and aesthetic disturbances, and result in excessive street maintenance requirements and in shortened overall street life.

Utility tunnels in some form have a history of over two hundred years in Europe. Portions of the existing London system were constructed coincident with the first buried utility systems in 1859 and utility lines were suspended in the existing Paris Great Sewer system at about the same time. The principal motivation for these facilities were to eliminate the ever increasing street cuts which cause great expense and interference to traffic flow. This was recognized very early. In 1864 the London Illustrated Daily News stated: "The object is to do away with the intolerable nuisances caused by the stoppage of thoroughfares when a careless workman happens to make a bad joint in a gas or water main, or whenever an accident happens". Not until recent years, however, has any deliberate large scale system been planned and installed. Spain, Germany, Russia and other european countries (as well as Japan) now have substantial comprehensive systems. In the United States and Canada, installations have been limited to college campuses and institutions, except for a few special purpose installations such as tunnels under rivers and far northern systems whose purpose is to prevent the freezing of water and sewer lines. Although some concern over the environment has motivated the construction of past utility tunnels, this now becomes an important consideration in our society. Surface utilities must be underground; traffic interference cannot be tolerated; utility services cannot be interrupted; air, land and water pollution must be curbed. The utility tunnel offers potential benefits in each of these areas. The review of past experience with utility tunnels and the investigations and studies provide an insight into the drivers affecting the applicability and feasibility of tunnel systems in various situations.

The prevalent practice of burying each utility in separate trenches across the street right-ofway is as outdated as overhead wires. The cost incurred due to the almost constant excavation of streets for maintenance and replacement, and the detrimental effects on urban environment are unjustifiable. There are-several more suitable alternates, each of which should be seriously evaluated by municipal engineers. Examples of these alternates are:

1. Common trench, where several utilities are grouped in a multi-layer single trench.

2. Common conduit, where one or more utilities are placed in multiple ducts in a single trench.

3. Utility corridor, which essentially is the joint use of a single utility right-of-way by two or more utilities outside the road right-of-way. 
4. Utility tunnel, which is an underground structure containing one or more utility systems, permitting the installation, maintenance, and removal of the system without making street cuts or excavations.

The method to be used by any community should be tailored to needs. Both the basic nature of the various utility systems and their in-tunnel requirements must be examined as part of the overall analysis of the feasibility of installing them in combined-use tunnels. The former considerations include such drivers as service requirements, network schemes, operational requirements and safety problems. However, in terms of quietness the utility tunnel is the best option for environmental reasons. Although the costs of utility tunnel systems can be quantified with a reasonable degree of accuracy for specific situations, benefits are much more difficult. Sufficient experience is not available to permit a reasonable assignment of monetary values to identifiable benefits. Examples of the foregoing are:

- $\quad$ Elimination of street noises, improvement of the aesthetic environment and improved property values are considered to be non-quantifiable, but identifiable benefits.

- $\quad$ Elimination of utility system damage due to cut-ins, elimination of utility system damage due to traffic and earth loads, and elimination of corrosion damage are considered to be benefits permitting a reasonable degree of assignment of monetary value.

- $\quad$ Elimination of traffic delays, reduction of street maintenance requirements and extension of street life are considered to be quantifiable benefits but sufficient evidence is not available to permit assignment of reasonable monetary values.

The increasing public pressure for quiet spaces that can offer high-quality urban environment is a key driver for municipal policies. However, it is significant to note that utility tunnel system studies conducted recently found economic justification based solely on tangible factors. The intangibles (noise and aesthetic considerations, traffic delays and disturbances due to street cuts, long term deterioration of streets, etc.) were not quantified (Canto-Perello, and Curiel-Esparza 2006). Today, however, we have a new dimension: environmental quietness-aesthetics. Quantity has made way for quality. People are willing to pay the price for a pleasing landscape. The theme seems to be "don't put it here" or "put it where I can't see it" and this demands a joint cooperative effort. From past experience we see that utility tunnels are well-accepted by single institutions like universities and hospital centers. In these institutions singular administrative control has literally forced the utilities to join together. One of the greatest drivers in the development of urban utility tunnel networks is the cooperation and coordination of all government and utility agencies so that a workable plan can be developed. Comparing the experience of many countries, the use of utility tunnels are closely bound to important and courageous political decisions. Local authorities take these 
decisions usually at historical moments, for example in urban planning for Olympic events like Tokyo and Barcelona.

\section{Municipal government and public agencies drivers}

The main difference between traditional and contemporary choice of location for activity is the fact that nowadays creative and talented people associate the attractive location with the quality of a place. As pointed by Sinkienè and Kromalcas (Sinkienè and Kromalcas 2010), this encourages the development and implementation of new municipal policy measures to attain a clear objective to increase the attractiveness of the city. Moreover, recent studies show that traffic has a significant impact on the quality of living environment (Botteldooren 2011). In addition, Gidlöf-Gunnarsson and Öhrström concluded from their research (GidlöfGunnarsson and Öhrström 2011) that it is also important to create attractive high-quality quiet courtyards and other shielded spaces that can offer urban residents a positively perceived sound environment, an attractive visual appearance, and opportunities for rest, play, social contact, and to do other activities. How and by whom the process is initiated influences its subsequent development, particularly in terms of citizen engagement or rejection. Municipal authorities play a central role in developing policies for urban underground space, particularly in terms of initial resources such as qualified personnel, guidance, information and publicity. But their mandate is primarily to act as a catalyst to some form of collaborative governance with private companies. These organizations can be analyzed under four basic features: specialization, coordination, centralization and scale.

A critical facilitator in the development of urban utility tunnel networks is the cooperation and coordination of all government and utility agencies so that a workable plan can be developed. In utility governance, coordination most naturally falls on the municipal agency in charge of the streets. While cooperation with the utility companies is essential, the local government must retain the authority to mediate when a conflict of interest arises. Municipal agencies and utility companies should designate persons from their staffs as utility tunnel coordinators. Their duty is to meet regularly and discuss the immediate as well as long range plans for the underground facility. This liaison eliminates the majority of conflicts that might otherwise arise. A long range plan should project twenty to thirty years into the future and should also be updated at regular intervals to make changes as they become necessary. It should be emphasized that utility companies should also have some long range plan in effect to compare their needs with those of the governing agency.

There are three main organizational arrangements underlying this driver. First, public ownership and jurisdiction (e.g. the city of Madrid); second, a government supervised but privately controlled utility corporation (e.g.: the city of Barcelona); and finally, utility tunnels under utility company or institution ownership (e.g.: universities, hospitals, military 
installations, nuclear plants, etc.). Public ownership appears to offer the widest choice of alternative methods. Such methods include bonding, several types of grant programs, and combinations. Financial sources available for private ownership are usually limited to conventional financing through issuance of stocks or bonds. Under the public sector management systems are direct municipal ownership and special authorities. Private management systems would include single-private, joint-private and condominium. Whatever the form of management, explicit ordinances, regulations or agreements must be established.

On the other hand, the incessant cutting of pavements to install or repair underground facilities causes traffic delays, poses safety hazards, pollutes the environment, creates esthetic detriments, reduces the useful life of pavements and limits access to abutting properties. When repairing one strand of spaghetti, workers sometimes damage another. Street construction and maintenance disrupt service and cause economic losses. Utility operations within street rights-of-way are also more costly and hazardous due to traffic interference and the need to avoid damage to other utility lines and to repair damage to pavements. In year 40 of a road life, it will have 2 pipe damages and repair construction points per $\mathrm{km}$. Overall it will have accumulated 30 to 34 repair or refurbishing works to rectify damages or make changes along each road $\mathrm{km}$ during these 40 years (Laistner and Laistner 2012). Elimination of street maintenance requirements and extension of street life can both facilitate municipal policies for sustainable urban underground space. These potential benefits result from the reduced requirements for maintenance of streets damaged and weakened by utility cuts and from overall longer street life before reconstruction is required. Monetary quantification in this case is much more difficult and depends on a variety of factors such as type of pavement and foundation, climate, and general nature of the street.

Public and private transportation systems are but additional utilities which serve the urban environment. In the past many have spoken of great losses due to the lack of comprehensive planning of all utilities which inhabit the urban street right-of-way. Surface transportation systems have been severely penalized by the myriad utility cuts that annually plague major cities. The inclusion of subsurface transportation systems, such as subways, walkways, or vehicular lanes, within utility tunnels is indeed questionable. This adds a severe dynamic force which could be injurious to utility systems as well as violating the security and the controlled atmosphere. Past experience indicates that utility tunnels and underground transportation systems should be separated, even if only by a common wall. In addition, the underground space sometimes holds archeological treasures which are now systematically protected (Godard 2004). This aspect of protecting heritage must in no case be neglected, and this constraint must be taken into account in the schedule of the utility tunnel projects, notably in order to allow for archeological excavations. In this respect, it should also be recognized that sustainable urban underground policies help protect archeological sites. 


\section{Financial and economic drivers}

Financial drivers may be defined as the feasibility of obtaining the necessary capital for construction of utility tunnel systems and establishing revenues for the recovery of capital and operating costs. Financial drivers for utility tunnels depend on reasonable quantification of certain benefits not now quantifiable due to lack of appropriate data and evidence. Whitout them, utility tunnels are not profitable. An example is found in the city of Besançon (France), where the initial investment for a utility tunnel was estimated at 1525 euros $/ \mathrm{m}$ while using traditional trenching were needed only 915 euros $/ \mathrm{m}$. The important items requiring quantification include elimination of traffic delays, reduction of street maintenance requirements and the extension of street life. Financial justification is most likely found in the higher density urban districts and in situations where massive reconstruction of streets, utility systems and buildings is performed. Although complex, the legal, ownership, regulatory and management problems are considered solvable. The more complex problems involve cost allocation for accounting and rate making purposes.

It is not possible to make a general statement as to the engineering-financial feasibility of utility tunnels because each situation will be different in terms of location, urban population and traffic density, utility systems to be installed, type and number of customers, costs of construction and many other factors. The test of economic feasibility of a given utility tunnel project requires a detailed engineering-financial analysis. Such an analysis should be based on quantifiable market factors only and should exclude consideration of the availability of money (such as federal or state grants). Only after the engineering-financial analysis proves a favorable benefit-cost ratio should the availability of finances be considered. The analysis should also be based on an acceptable rate of return and not on the current interest rate of municipal bonds.

In addition, one of the more difficult problems of space is the provision of room for expansion and future utility systems. If sufficient is not provided, the street will have to be torn up and the main purpose of the utility tunnel negated. On the other hand, too much expansion space will add to the burden of economic justification. Provision of vault space for utility system auxiliary equipment like electric power transformers will require that the tunnel section be enlarged at intervals, that the required space be made available in enlarged rooms at tunnel intersections, that separate vaults be constructed exterior to the tunnel, and that space be provided in adjacent building basements or combinations. Careful planning of vault space requirements plus attention to future requirements will be important to avoid extra costs.

The utility tunnel concept includes several apparent benefits which are not readily quantifiable in the ordinary sense. These include the value of time saved in the absence of street obstructions, savings in street maintenance and the value of lives saved through 
accident reduction. Although having a theoretical monetary value, no widely accepted method of assessment has been established. Such benefits are likely to be critical drivers to the benefit-cost analysis of a utility tunnel project. The goal of a sound financial plan for utility tunnels should be to equitably distribute all construction, operating and maintenance costs to those who benefit from its existence. In Geneva (Switzerland), a method of allocating expenses has been proposed depending on areas reserved or used. The city council provides $20 \%$ for in-tunnel sewers and $18 \%$ for reserved space, Swisscom provides $12 \%$ for telecommunication lines, the public transport company covers $2 \%$, the electrical companies $26 \%$ and the public water company $22 \%$. It is not likely that a general plan for defraying this cost can be formulated. Rather, each case must be viewed individually utilizing basic guidelines and exercising reasonable judgment.

A utility tunnel will be expected to last many years. A life of 50 years is not unreasonable for a well built reinforced concrete underground facility. During this period of time many changes will occur in types and volumes of utility services and locations of sources and services. If proper planning is not accomplished, streets will have to be dug up for new services and perhaps for replacement of the entire tunnel, thus negating the major tunnel advantage. The provision of internal expansion space has been discussed previously. There are however, other matters requiring attention. Some method of providing for future service connections and enlargement of original ones must be devised. This must be accomplished without disturbing street surfaces. Possibilities include drilling from within the tunnel to the curb line or beyond and providing oversize capacity service ducts leading to every conceivable abutting property during original construction. Expanded systems and new systems will require vault space for auxiliary equipment. A reasonable amount of future vault space should be provided during original construction to preclude having the street dug up and the primary purpose of the tunnel system negated.

\section{Utility company drivers}

The benefits of utility tunnels to individual utility companies can probably be identified with acceptable precision, given comprehensive analysis. How these benefits can be translated into value to the utility is far more difficult. The valuation of utility company property is exceedingly complex, and privately owned public utilities are not marketed frequently enough to establish value criteria. Therefore, the valuation procedures that are in existence have come about because of ad valorem taxation and ratemaking. Investment in utility tunnels, to the extent that regulated public utilities share in ownership, will add to rate bases. However, regulatory commissions will be concerned with the prudence and reasonableness of utility tunnel costs. Some form of rental agreement will be required. Many versions might be drawn up, using existing types of agreements for joint use of poles, trenches, etc. as a base. Especially interesting is the case of Paris - La Défense utility tunnels managed by EPAD 
(Établissement public pour l'aménagement de la région de la Défense), which fixes the amount of the royalties, contrary to what occurs on a public road. These fees include two terms. An amount corresponding to the occupation of (part that can be likened to a rent) set at 9.50 euros/year $/ \mathrm{m}$, and a proportionate share of the volume occupied by the lines (except that you can assimilate condominium fees) which varies from 3 euros/year/m to 13 euros/year/m.

Some single entity must be made responsible not only for initial construction but also for security, access control, and operation and maintenance of ancillary equipment throughout the life of the project. For example, a public company is responsible for the management of 17 $\mathrm{km}$ of utility tunnels in the city of Brno (Czech Republic) with an operating cost of one million euros per year. Occupants cover $45 \%$ of costs (rental fee), the City Council covers $29 \%$ and the managing company covers $26 \%$ of its own resources. When two or more private owners were involved, one could be designated by agreement as having management responsibility and authority with the others contributing their fair share of management expenses. It would also be possible for two or more separate utilities to form a separate management company. The functions of the management organization, public or private, would include:

- $\quad$ Procurement of required permits and easements and coordination with other state and local authorities.

- $\quad$ Planning, design, and construction.

- Establishment of criteria for the design, installation and operation of all utility systems to be installed in the tunnel.

- Coordination of installation of utility systems.

- Operation and maintenance of all ancillary systems such as drainage, lighting, ventilation, fire detection, and gas detection.

- $\quad$ Provision for security and access control.

- $\quad$ Establishment and collection of rates.

One of the most complex problems in any joint undertaking for construction or use of utility tunnels is the manner of handling any liability which results from the construction, maintenance and operation of the facility. Nowadays, some utility companies are reluctant to occupy the same underground space with other companies. This seems to stem partially from the fear of greater exposure to liability in connection with utilities of other companies or with regard to third parties. Negligence in the construction, maintenance or operation of a utility tunnel could present difficult issues which can only be resolved in court. But, as with any other type of previous technical undertaking, this should not be a deterrent to the feasibility of a utility tunnel program. Failure of monitoring, detection and other safety devices also could pose liability problems, but the greater exposure to liability will probably result from human acts or inactions, i.e., the negligence of any individual who is working in the tunnel or from unauthorized personnel who may be in the tunnel. The problems and legal ramifications resulting from such negligence and any intervening causes and effects, in principle, should be 
the same as the current law on negligence. Joint construction and joint use agreements should provide for liability insurance programs. When legally possible and practical, contract provisions should contain clauses to cope with liability problems; but undoubtedly, this could be a difficult task to accomplish. Very explicit agreements as to the rights and obligations of all participants will be necessary, whatever the form of management organization.

Adequate attention must be given in the design of utility tunnel systems to the requirements of utility system installation, operation and maintenance. Most utility system material is relatively large and heavy and provisions must be made for adequate material and personnel access, internal handling and adequate tunnel working room. Individual utilities must be consulted in detail, otherwise the potential ease of maintenance and service operations in the tunnel as compared to conventional installations will be negated. A proper working environment must also be provided in the tunnel to permit efficient maintenance work. The safety of personnel working in the tunnel system is of concern. Careful training programs are required to insure the safety of workmen handling one utility from hazards inherent in other utilities. Special access control systems are required to exclude unauthorized persons. Adequate safety equipment, firefighting equipment and hazard detection and alarm systems must be provided. Since the tunnel will contain all essential utilities serving a large area, it may be an inviting target for sabotage or vandalism. Appropriate tunnel security provisions are required.

Strict rules for entry and activity within the tunnel must be established. Such rules should include: rules governing entry (e.g. single individuals should not be permitted entry; written permits required); rules governing the use of tools and equipment (lights, welding systems, open flames, etc.); rules governing the testing for gas before entry in tunnels not having powered ventilation. An internal tunnel telephone system should be installed for use during emergencies as well as utility system communication. Automatic gas and fire detection systems should be provided. A fire alarm system should also be installed. Automatic systems to detect substantial leaks in the water supply system should also be included. Because of assembly of a large number of utility systems in a small space, the utility tunnel might be an inviting target for vandalism or sabotage. Special administrative and physical precautions would be required to prevent entry by unauthorized persons. Direct entry from buildings served by lateral tunnels should be prevented by bulkheads or suitable locked doors. Television monitoring systems, sensing devices and other security systems might be justified for very large utility tunnel facilities. For example, Madrid has $150 \mathrm{~km}$ of utility tunnels; this infrastructure housed 4,650,387 meters in length of utilities. The Governing Board has approved an expenditure of 3.107.323 euros for two years for the maintenance, operation and management of these utility tunnels. Among the tasks that develop within its contracts include the inspection and supervision of the utility tunnels, in order to gather information on the state of the infrastructure as well as the security and emergency care. These facilities are constantly ( 24 hours a day, 365 days a year) controlled from a control center, using 110 mobile and 210 
fixed cameras, 1900 fire detection systems and 600 alarm devices. Consideration might be given to sectionalizing the tunnel to limit damage in case of fire, large gas leaks, or water main rupture. Sectionalizing would be provided by bulkheads at intervals. Utility line penetrations and personnel doors would require special attention. In addition, the utility tunnel must provide a cool, dry, ventilated and well lighted environment for the safety .and comfort of maintenance and repair personnel and to prevent deterioration and corrosion of utility systems equipment.

\section{Conclusions}

The sum of the need for quietness and lessen aesthetic and environmental impacts; the effect of street cuts on traffic and people; the proliferation of utility types, services and expansions; the scarcity and cost of available rights-of-way; the increasing population densities of urban areas; and other considerations serve to question the appropriateness of past and present utility installation practices in our cities. Utility tunnels appear as a solving problem technique for the sustainable future of urban underground space. The review of past experience and the investigations and studies provide an insight into the drivers affecting the applicability and feasibility of utility tunnel systems. Without a clear sense of the key drivers for change in municipal policies, public authorities and private managers will not be able to take the decisions that allow for effective action.

The success of any utility tunnel project will depend upon the cooperation and agreement of all concerned. Through all phases of planning, financing, construction and operation, the policies and practices of government, public and private utilities and the various regulatory bodies must be considered. Guarantees of impartial treatment for all users will also be necessary. Private utilities must be assured that no preferential treatment will be granted to municipal utilities by a municipal managing authority. A number of technological problems relating to the compatibility of a variety of utility systems in close proximity inside a tunnel need to be resolved. Safety and security systems need to be engineered into the systems. Technological problems, however, do not appear insurmountable. Institutional problems seem to pose the most significant restraints at present. The consensus is that the facilities should be owned and managed by a public agency with space rented to the utility companies.

Financing drivers are crucial for urban underground in municipal planning. One estimate indicates that placing utility lines in a tunnel approximately doubles the initial capital investment. Expectations are that these costs could be recovered in time through reduced utility and street operation and maintenance costs. The real benefits from reduction in traffic delays will depend strongly on the traffic volume and the incidence of street cuts. Each case will be different and will require detailed data collection and analysis. Many of the apparent benefits of the utility tunnel concept are not quantifiable in direct monetary terms. Consider 
the detrimental effects of noise, and the effect on abutting properties and users of the street, and the loss becomes very great. The presence of such benefits in a proposed project may be sufficient to provide justification even though the benefit-cost ratio, based on directly quantifiable factors, is unfavorable.

The use of utility tunnels, as a major capital investment in city planning, should be promoted in municipal policies to achieve quietness in our urban environment. Utility tunnels became significant for preventing the need to dig up streets for statutory services. The question then is: How do you get these improvements on the drafting boards when they must compete with so many other demands for money? Basically, the answer is that the people must ask for them. A popular pastime today is to accuse engineers of being shortsighted in his approach to the city he serves, and of considering it only within obsolete parameters. If we as engineers can overcome this weakness, then we can expect readier acceptance of worthwhile improvements in the urban planning and in the quality of life.

\section{References}

Abdul Salam AO. 2007. Safety in automated transportation tunnels, Proceedings of the 15th Mediterranean Conference on Control and Automation, Athens.

Booi H, Berg F. 2012. Quiet Areas and the Need for Quietness in Amsterdam. International Journal of Environmental Research and Public Health 9(4): 1030-1050.

Botteldooren D, Dekoninck L, Gillis D. 2011. The Influence of Traffic Noise on Appreciation of the Living Quality of a Neighborhood. International Journal of Environmental Research and Public Health 8(3): 777-798.

Cano-Hurtado JJ, Canto-Perello J. 1999. Sustainable development of urban underground space for utilities. Tunnelling and Underground Space Technology 14(3): 335-340.

Canto-Perello J, Curiel-Esparza J. 2001. Human factors engineering in utility tunnel design. Tunnelling and Underground Space Technology 16(3): 211-215.

Canto-Perello J, Curiel-Esparza J. 2003. Risks and potential hazards in utility tunnels for urban areas. Proceedings of the Institution of Civil Engineers - Municipal Engineer 156(1): 51-56.

Canto-Perello J, Curiel-Esparza J. 2006. An analysis of utility tunnel viability in urban areas. Civil Engineering and Environmental Systems 23(1): 11-19.

Canto-Perello J, Curiel-Esparza J, Calvo V. 2009. Analysing utility tunnels and highway networks coordination dilemma. Tunnelling and Underground Space Technology 24(2): 185189. 
Carmody J, Sterling R. 1993. Underground Space Design. Van Nostrand Reinhold, New York.

Choon SW, Siwara C, Pereira JJ, Jemainc AA, Hashima HS, Hadib AS. 2011. A sustainable city index for Malaysia. International Journal of Sustainable Development \& World Ecology 18(1): 28-35.

Curiel-Esparza J, Canto-Perello J. 2005. Indoor atmosphere hazard identification in person entry urban utility tunnels. Tunnelling and Underground Space Technology 20(5): 426-434.

Curiel-Esparza J, Canto-Perello J. Calvo MA. 2004. Establishing sustainable strategies in urban underground engineering. Science and Engineering Ethics 10(3): 523-530.

Duffaut P. 1996. Paris conference examines the "Rightful" Place of the underground space in the modern city. Tunnelling and Underground Space Technology 11(1): 126-130.

Duffaut P, Labbe M. 2002. From underground road traffic to underground city planning, in Proceedings of the International Conference Urban Underground Space: a Resource for Cities, Torino.

Gidlöf-Gunnarsson A, Öhrström E. 2010. Attractive "Quiet" Courtyards: A Potential Modifier of Urban Residents' Responses to Road Traffic Noise? International Journal of Environmental Research and Public Health 7(9): 3359-3375.

Godard JP. 2004. Urban underground space and benefits of going underground, Proceedings of the World Tunnel Congress, International Tunnelling Association, Singapore.

Godard JP. 2008. Should we / Can we avoid Underground Mass Transit Systems? Proceedings of the World Tunnel Congress, International Tunnelling Association, Agra.

ITACUS. 2011. Sustainable Urban Underground Development. International Tunnelling Association, Lausanne.

Laistner A, Laistner H. 2012. Proven sustainability above and below ground, Proceedings of the 17th International Conference on Urban Planning and Regional Development in the Information Society, Schwechat.

Oude EHI. 1992. Underground space for utilities. Proceedings of the International Conference on Underground Space and Earth Sheltered Structures, Delft University Press, Delft.

Sinkienè J, Kromalcas S. 2010. Concept, Directions and Practice of City Attractiveness Improvement. Viešoji Politika ir Administravimas 31(1): 147-154.

Sterling RL, Godard JP. 2000. Geoengineering Considerations in the Optimum Use of Underground Space, Proceedings GeoEngineering, Melbourne.

Steurera R, Bergerb G. 2011. The EU's double-track pursuit of sustainable development in the 2000s: how Lisbon and sustainable development strategies ran past each other. International Journal of Sustainable Development \& World Ecology 18(2): 99-108. 
Thibault S, Trépanier M, Fougères D. 2003. The urban underground of Montreal: the commission of electrical and public services. Canadian Journal of Urban Research 12(1): 77101.

Wang JH, Koizumi A, Liu X. 2008. Advancing sustainable urban development in China. Proceedings of the Institution of Civil Engineers - Municipal Engineer 161(1): 3-10.

Zhang JC, Ding XM, Pang, YS, Li WP, Tong HW, Zheng XC, Xu Y. 2009. Analysis for development and utilization of underground space in Guangzhou. Gongcheng Lixue Engineering Mechanics 26(2): 106-114. 


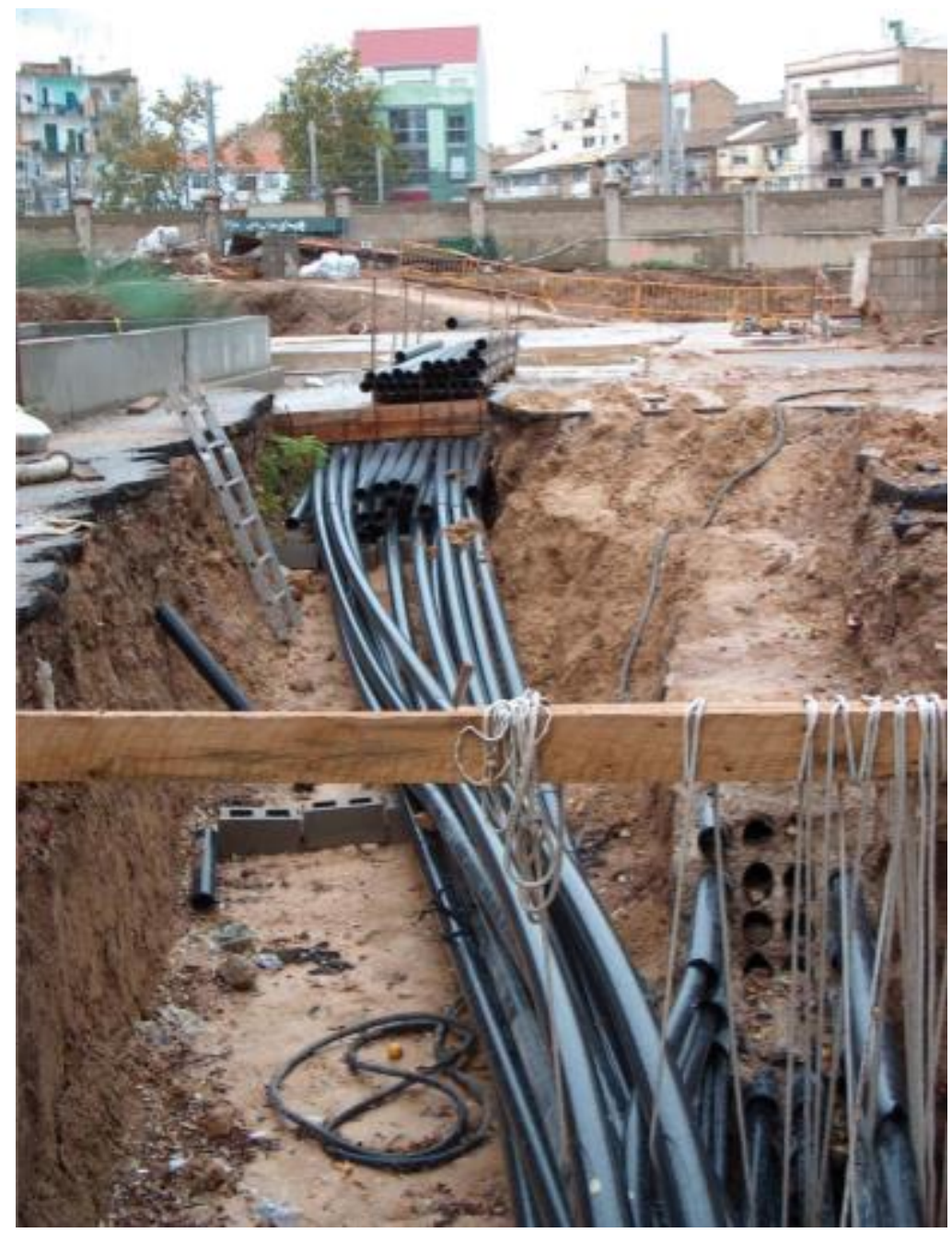

Figure 1. Placement of utility services underground is not generally accomplished in any systematic manner resulting in a veritable maze in high density urban areas 


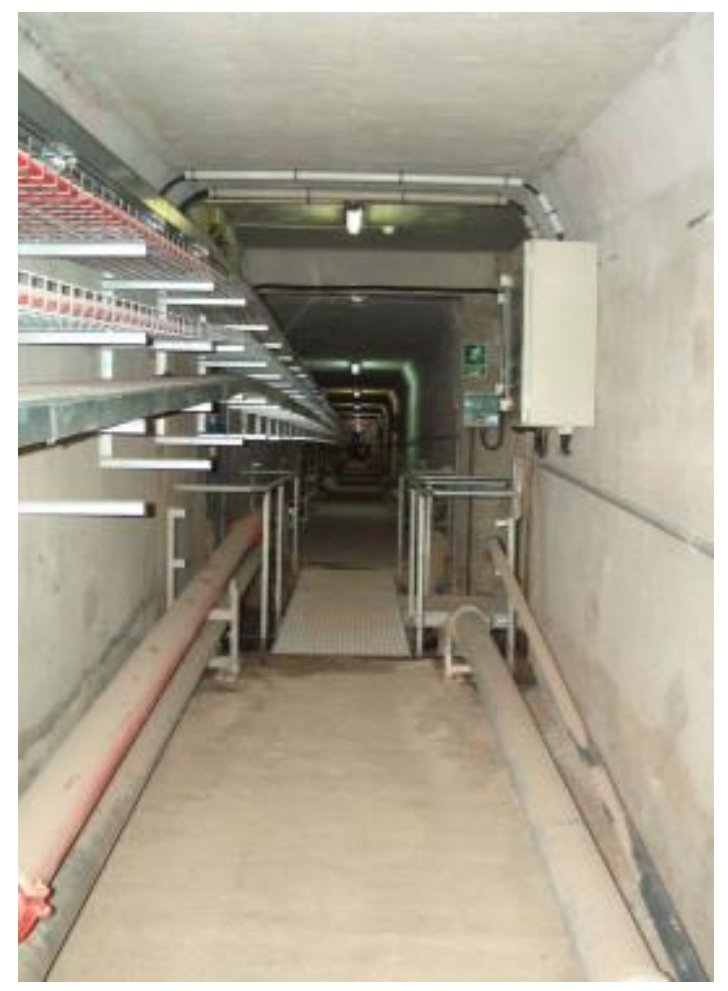

Figure 2. Cross-section of a typical utility tunnel

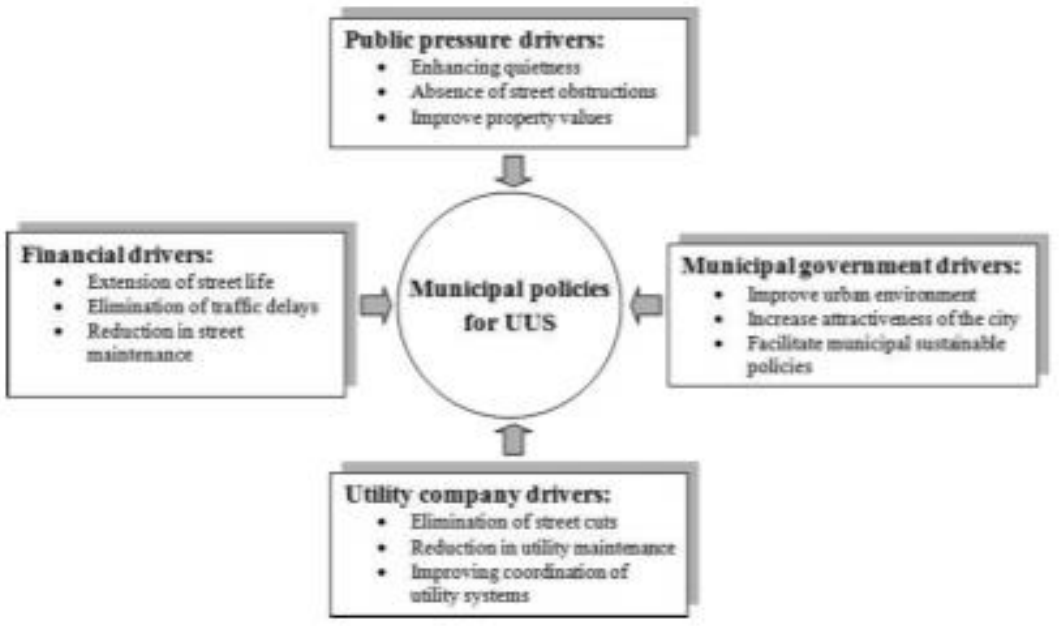

Figure 3. Key drivers to innovate in municipal underground policies 